\title{
Surface Reactivity of Titania-Vanadia Mixed Oxides Under Oxidizing Conditions
}

\author{
Xin Song $^{1} \cdot$ Helmut Kuhlenbeck ${ }^{1} \cdot$ Hans-Joachim Freund ${ }^{1}$
}

Published online: 11 May 2018

(c) The Author(s) 2018

\begin{abstract}
The surface structure and reactivity of $\mathrm{TiO}_{2}(110)$ with $1-15 \%$ of admixed vanadium were studied using thermal desorption spectroscopy, scanning tunneling microscopy, low-energy electron diffraction, and X-ray photoelectron spectroscopy with the methanol partial oxidation as the reactivity test reaction. Prior to the experiments the sample was oxidized at elevated temperatures with $\mathrm{O}_{2}$ of different pressures up to $10^{-6}$ mbar. As shown in a preceding publication (Song et al. in Surf Sci 653:181-186, 2016), vanadium leads to an increased reducibility of the mixed oxide, which resulted in the simultaneous presence of reduced and oxidized structural elements at the surface. At low vanadium concentrations (a few percent) small vanadia clusters with $\mathrm{V}^{4+}$ form above the fivefold Ti rows at the surface together with short vanadium decorated strands along [001]. These types of structure promote the partial oxidation of methanol towards formaldehyde at $550 \mathrm{~K}$. At higher vanadium concentrations the vanadia aggregates at the surface contain $\mathrm{V}^{5+}$ in addition to $\mathrm{V}^{4+}$. They produce formaldehyde already at $480 \mathrm{~K}$ and below. The oxidized $\mathrm{TiO}_{2}(110)$ layer with admixed vanadium releases QMS-detectable amounts of $\mathrm{O}_{2}$ already at a temperature of about $450 \mathrm{~K}$, which is about $80 \mathrm{~K}$ below the corresponding temperature for $\mathrm{TiO}_{2}(110)$ without vanadium. This is attributed to the increased reducibility of rutile with admixed vanadium.
\end{abstract}

Keywords $\mathrm{TiO}_{2}(110) \cdot$ Vanadium $\cdot$ Doping $\cdot$ Methanol $\cdot$ Formaldehyde

\section{Introduction}

Vanadium oxides are catalytically active for many reactions involving oxygen transfer like the partial oxidation of alcohol. They are often used in combination with other materials, either deposited on a substrate or as part of a chemical compound like vanadium pyrophosphate, which plays a relevant role for the catalytic oxidation of butane to maleic anhydride $[1,2]$. It has been shown that vanadium oxides supported on titania powder catalytically produce acetaldehyde from ethanol with a high yield at a low reaction temperature of $390 \mathrm{~K}$ [3]. For zirconia, ceria and alumina supports the yields were smaller than for the titania support and the reaction temperatures were higher. These examples demonstrate clearly that the substrate material affects the catalytic performance and

Helmut Kuhlenbeck

kuhlenbeck@fhi-berlin.mpg.de

1 Chemical Physics Department, Fritz Haber Institute of the Max Planck Society, Faradayweg 4-6, 14195 Berlin, Germany that titania (mostly anatase) substrates have a positive impact onto the catalytic process.

The crucial relevance of the substrate has been studied in detail for vanadia species on $\mathrm{CeO}_{2}(111) / \mathrm{Ru}(0001)$ thin films [4-6]. A low methanol to formaldehyde conversion temperature of $370 \mathrm{~K}$ was found for a $\mathrm{VO}_{2}$ surface species. It was shown that support and vanadia species act cooperatively with the cerium atoms accepting electrons in their $4 \mathrm{f}$ states, thus stabilizing the 5+ oxidation state of the vanadium atoms during the reaction.

Structural and chemical model studies have been conducted for rutile $\mathrm{TiO}_{2}(110)$ single crystal substrates covered with vanadium $[7,8]$ or vanadia [9-18] layers. Scanning tunneling microscopy (STM) experiments have shown that the deposition of small amounts of metallic vanadium without subsequent oxidation leads to atoms preferentially located in 'upper threefold hollow' sites where the atoms are bonded to two bridging oxygen atoms and one threefold coordinated basal oxygen atom [8]. Vanadia clusters, prepared by deposition of vanadium in an oxygen ambient atmosphere were found to be located on top of the fivefold coordinated $\mathrm{Ti}$ rows of the substrate at low coverage, while for coverages 
larger than $2 \mathrm{ML}$ (monolayers) it was reported that vanadia layers grow epitaxially on the $\mathrm{TiO}_{2}(110)$ surface [14]. Formaldehyde production via partial methanol oxidation on vanadia covered $\mathrm{TiO}_{2}(110)$ surfaces has been observed at temperatures ranging from 300 to $642 \mathrm{~K}[12,16,17]$. In these studies the vanadium oxide layers were prepared with the substrate maintained at a mild temperature (300-500 K), probably since vanadium quickly diffuses into the substrate at temperatures above $\sim 600 \mathrm{~K}[7,8]$. Powder catalysts may be prepared at a higher temperature such as $773 \mathrm{~K}$ [3] which means that diffusion may play a role.

The goal of the study reported here was to identify parameters relevant to catalysis at the surface of a mixed oxide model system, with the example of methanol on a $\mathrm{TiO}_{2}(110)$ substrate with admixed vanadium. Confinement of the vanadium atoms to a surface-near volume with a limited size prevented that the vanadium atoms diffused into the substrate. Such a confinement may be required to realistically mimic a supported catalyst, where the substrate might be a powder particle with a small volume into which part of deposited metal may dissolve. After several tries we could show that such a confinement can be realized with a $\mathrm{Ta}+\mathrm{Ti}$ mixed oxide interlayer between the titanium oxide overlayer with admixed vanadium and the $\mathrm{TiO}_{2}(110)$ substrate [19].

The surface structure was studied with low-energy electron diffraction (LEED) and STM, the electronic structure was investigated with X-ray photoelectron spectroscopy (XPS), and the surface reactivity was characterized with temperature programmed desorption (TPD). Such an approach permits to correlate the geometric and electronic structure with the surface reactivity, i.e. to establish structure-reactivity relationships. In a preceding publication we have discussed the case of mixed $\mathrm{Ti}+\mathrm{V}$ oxide layers for the case of reducing preparation conditions. In this publication we treat the effect of oxidation onto the surface structure, the electronic properties and the surface reactivity with the example of the partial methanol oxidation.

\section{Experimental Methods}

The studies were performed in a commercial Omicron ultrahigh vacuum (UHV) system (base pressure $\sim 1 \times 10^{10} \mathrm{mbar}$ ) equipped with facilities for XPS with an Omicron $\mathrm{Mg} / \mathrm{Al}$ dual cathode X-ray source and an Omicron EA 125 electron energy analyzer, LEED with an Omicron LEED system, TPD with a QMS (quadrupole mass spectrometer) from Thermo, and STM with a Omicron STM 1 room temperature microscope. XPS was used to determine the oxidation states and vanadium concentrations, which are given as the ratios of the cross-section weighted V2p intensities and the sum of the cross-section weighted V2p and Ti2p intensities. XPS spectra were recorded at normal and off-normal electron exit angles $\left(0^{\circ}\right.$ and $60^{\circ}$ with respect to the surface normal) to vary the surface sensitivity. The QMS was mounted in a differentially pumped housing with a small opening near to the ionizer [20]. During TPD the sample was placed in front of this opening at a distance of not more than $1 \mathrm{~mm}$ in order to reduce contributions to the TPD spectra from gases desorbing from the sample holder. The STM images shown here were processed with the WSxM software [21].

The preparation of the reduced $\mathrm{Ti}+\mathrm{V}$ mixed oxide with different vanadium concentrations has been described elsewhere [19]. Briefly, the reduced $\mathrm{Ti}+\mathrm{V}$ mixed oxide film ( $\sim 100 \AA$ thick) was prepared on a rutile single crystal substrate with a $\mathrm{Ti}+\mathrm{Ta}$ mixed oxide layer ( $20 \%$ tantalum, $\sim 30 \AA$ thick) between the substrate and the overlayer [19]. The tantalum containing layer blocks the diffusion of vanadium and titanium. Both mixed oxide layers were prepared by co-deposition of the involved metals in an oxygen ambient atmosphere $\left({ }^{18} \mathrm{O}, 1 \times 10^{-6} \mathrm{mbar}\right)$ at $800 \mathrm{~K}$. This as-prepared sample was then annealed in ultrahigh vacuum $\left(2 \times 10^{-10} \mathrm{mbar}\right)$ at $800 \mathrm{~K}$ for $10 \mathrm{~min}$ to produce a reduced $\mathrm{Ti}+\mathrm{V}$ mixed oxide layer. The concentration of vanadium in the reduced layer was tuned by adapting the vanadium deposition time, keeping the deposition rate constant. To obtain an oxidized layer, the reduced layer was annealed in oxygen $\left({ }^{18} \mathrm{O}, 1 \times 10^{-6} \mathrm{mbar}\right)$ at $600 \mathrm{~K}$ for $10 \mathrm{~min}$. The oxygen supply was switched off after annealing when the crystal had reached a temperature of $420 \mathrm{~K}$.

In the adsorption experiments $50 \mathrm{~L}\left(1 \mathrm{~L}=1 \times 10^{-6}\right.$ Torr s) of methanol $\left(\mathrm{CH}_{3}{ }^{16} \mathrm{OH}\right)$ were dosed at room temperature. TPD spectra of methanol adsorbates were recorded between 290 and $800 \mathrm{~K}$ with a constant heating rate of $0.5 \mathrm{~K} \mathrm{~s}^{-1}$. The masses 33 and 31 were selected to determine the concentrations of ${ }^{16} \mathrm{O}$ and ${ }^{18} \mathrm{O}$ in methanol released from the surface. Similarly, masses 32,34 , and 36 were selected to track the isotopic composition of desorbing oxygen molecules. Since $\mathrm{C}^{18} \mathrm{O}$ (mass 30) was found in the residual gas atmosphere of the experimental chamber, mass 29 instead of mass 30 was selected for the identification of formaldehyde. Contributions of methanol to the mass 29 spectra were subtracted prior to plotting the spectra according to

$I_{\text {plotted }}^{\text {mass 29 }}=I_{\text {raw }}^{\text {mass 29 }}-C^{\text {mass 29 }} \times I_{\text {raw }}^{\text {methanol }}$

with the factor $C^{\text {mass } 29}$ being calculated from the mass fragmentation pattern of methanol and sensitivity factors published by the manufacturer of the mass spectrometer.

\section{Results and Discussion}

We have shown previously that annealing of the $\mathrm{Ti}+\mathrm{V}$ mixed oxide in UHV results in a distribution of $\mathrm{V}$ below the surface of the thin film [19]. Contrary to this, annealing 
of the mixed oxide in an oxygen ambient atmosphere leads to an agglomeration of vanadium at the surface. Figure 1a displays V2p XPS spectra measured at normal $\left(0^{\circ}\right)$ and offnormal detection angles $\left(60^{\circ}\right)$ of oxidized $\mathrm{Ti}+\mathrm{V}$ mixed oxide thin film samples with different vanadium concentrations. From fits of Ti2p and V2p spectra, like those shown in Fig. 1b, the concentrations of vanadium have been computed for the two electron emission angles (Table 1). All concentrations determined after oxidation are higher than the corresponding concentrations before oxidation, which shows that vanadium moves towards the surface when the sample is oxidized. The concentrations at the very surface of the oxidized samples are probably higher than those below as concluded from the higher vanadium concentrations determined for the more surface-sensitive off-normal spectra.

XPS shows that $\mathrm{V}^{5+}$ is found at the surface of the oxidized samples, especially for the highest vanadium concentration (14.1\%), in addition to $\mathrm{V}^{4+}$ and $\mathrm{V}^{3+}$, which are the only vanadium oxidation states in reduced samples. The oxidation states were identified by comparison of fitted binding energies with published data [10, 23-25]. Vanadium concentrations given in the following discussion are rounded numbers determined from measurements at an electron emission angle of $60^{\circ}$ if not noted otherwise.

The structure of the oxidized samples was characterized with STM and LEED. The STM images in Fig. $2 a$ and $b$ were recorded from the same area on a $\mathrm{TiO}_{2}$ layer with $1 \%$ of vanadium, but with different bias voltages. Figure $2 \mathrm{a}$ was recorded with a bias voltage of $+2.5 \mathrm{~V}$. Three different types of protrusions may be recognized in the image: bright spots with a height of $0.5 \AA$ between the bright rows (one of them is marked by a circle), bright spots with a height of $0.7 \AA$ on the bright rows (one of them is marked by a square) and features with a height of $2.0 \AA$ on the bright rows (one of them is marked by a pentagon). The bright spots between the bright Ti rows are attributed to bridging oxygen vacancies (BOV's).

The image shown in Fig. $2 b$ was recorded with a voltage of $+1.5 \mathrm{~V}$. In this image the BOV's are barely visible while the other two features are clearly observable. The bright protrusion marked by the square is attributed to an oxygen adatom since it has the same appearance as oxygen ad-atoms on an oxidized $\mathrm{TiO}_{2}(110)$ thin film [26]. The bright spot marked by a pentagon is higher than the oxygen ad-atom and was not observed on the pure $\mathrm{TiO}_{2}$ thin film, which is why we assign this type of feature to an aggregate involving vanadium ions.

Figure 2c displays a STM image of a layer with $3 \%$ of vanadium. Apparently the density of bright spots with a height of $2.0 \AA$ is higher, which adds weight to the assumption that aggregates of this type contain vanadium. In addition to this type of structure a bright short rod with a height
Fig. 1 a V2p XPS core level spectra of different oxidized $\mathrm{Ti}+\mathrm{V}$ mixed oxide layers (labeled (i)-(v)) measured at detection angles of $0^{\circ}$ and $60^{\circ}$ with respect to the surface normal. b V2p spectra of sample (v) recorded at $60^{\circ}$ before and after oxidation together with fits employing Shirley type backgrounds [22] and 2 or 3 Gaussian-Lorentzian functions, respectively
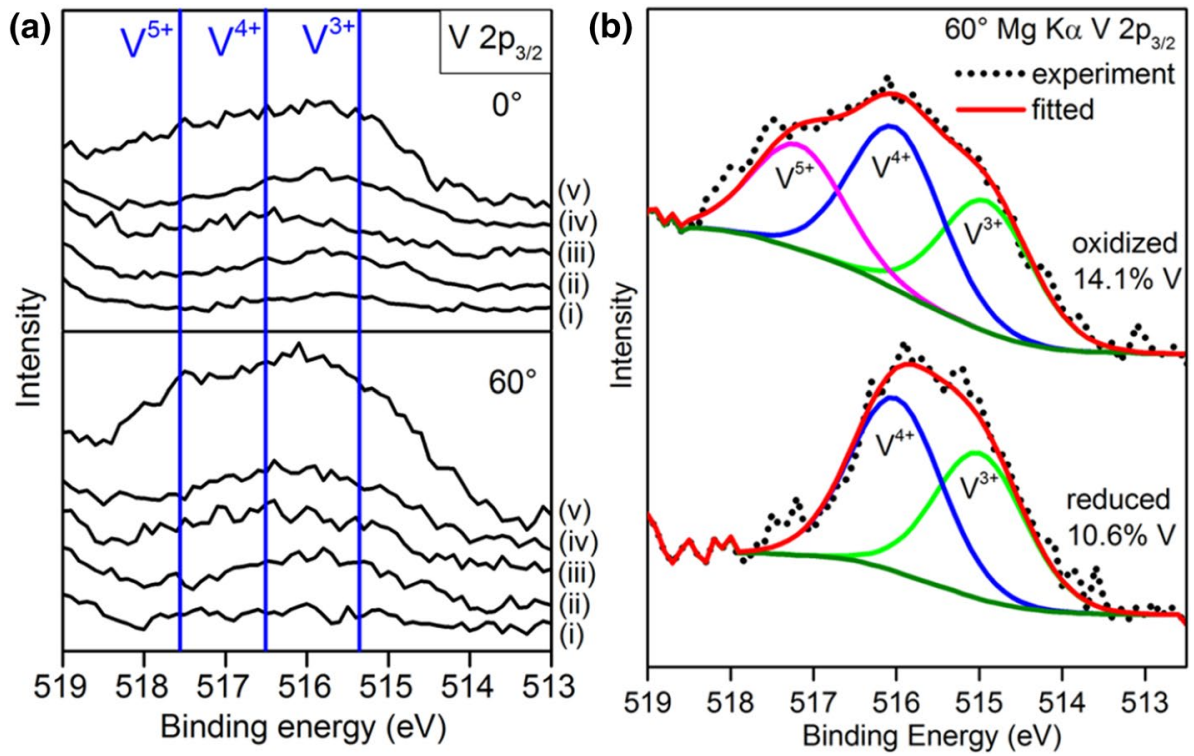

Table 1 Vanadium concentrations of the $\mathrm{Ti}+\mathrm{V}$ mixed oxide layers (i)-(v) before and after oxidation

\begin{tabular}{llllllr}
\hline & Detection angle & (i) & (ii) & (iii) & (iv) & (v) \\
\hline Reduced & $0^{\circ}$ & $0.8 \%$ & $1.5 \%$ & $2.3 \%$ & $3.5 \%$ & $7.9 \%$ \\
& $60^{\circ}$ & $1.2 \%$ & $2.2 \%$ & $3.2 \%$ & $4.4 \%$ & $10.6 \%$ \\
Oxidized & $0^{\circ}$ & $1.0 \%$ & $2.6 \%$ & $3.7 \%$ & $4.3 \%$ & $10.8 \%$ \\
& $60^{\circ}$ & $1.4 \%$ & $3.1 \%$ & $4.8 \%$ & $5.8 \%$ & $14.1 \%$ \\
\hline
\end{tabular}




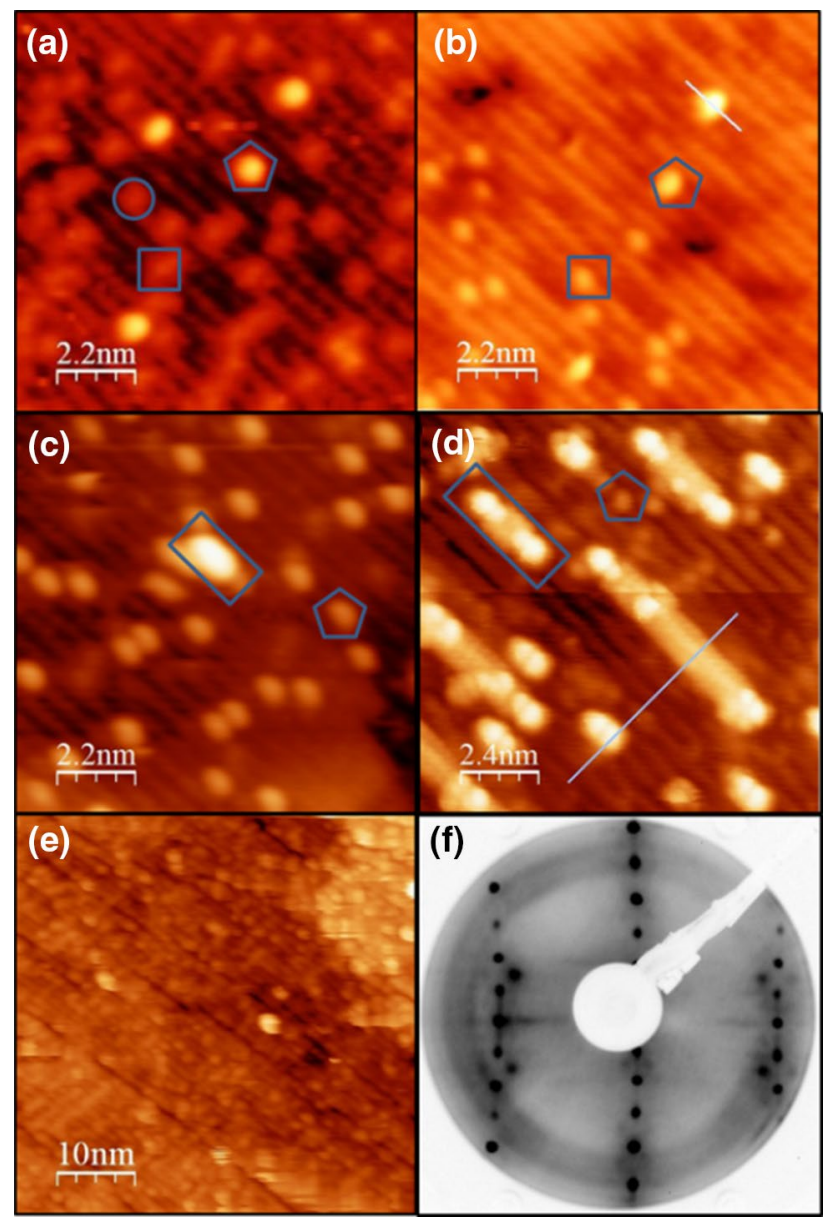

Fig. 2 STM images and a LEED pattern of oxidized $\mathrm{TiO}_{2}(110)$ layers with admixed vanadium. a STM image of a $\mathrm{TiO}_{2}$ layer with $1 \%$ $\mathrm{V}(+2.5 \mathrm{~V}, 0.1 \mathrm{nA})$. b STM image of the same area as (a), but with a bias voltage of $+1.5 \mathrm{~V}(0.1 \mathrm{nA})$. c STM image of a $\mathrm{TiO}_{2}$ layer with $3 \% \mathrm{~V}(+2.5 \mathrm{~V}, 0.1 \mathrm{nA})$. d STM image of a $\mathrm{TiO}_{2}$ layer with $6 \% \mathrm{~V}$ $(+2.5 \mathrm{~V}, 0.1 \mathrm{nA})$. e STM image of a $\mathrm{TiO}_{2}$ layer with $14 \% \mathrm{~V}(+3.5 \mathrm{~V}$, $0.03 \mathrm{nA}$ ). $\mathbf{f}$ LEED pattern of a $\mathrm{TiO}_{2}$ layer with $14 \%$ of vanadium

of $3 \AA$ and a length of $\sim 15 \AA$ is found at the surface (marked by the rectangle). Structures of this type have been observed recently at the surfaces of reduced thin films with admixed vanadium [19]. These structures indicate a reduction of the layer and were identified as " $\mathrm{Ti}_{2} \mathrm{O}_{3}$ rods", which are also found on heavily reduced $\mathrm{TiO}_{2}(110)$ surfaces with a $(1 \times 2)$ reconstruction [27-29]. When the vanadium content is increased then the density and the length of these structures increases as demonstrated by Fig. 2d, which shows a STM image of a mixed oxide layer with $6 \%$ of vanadium. Contrary to the case of reduced layers, where the rods have a homogeneous appearance [19], there are protrusions on the rods in the case of the oxidized layer, which we attribute to oxidized vanadium.

The rods and BOV's are indicators for reduction and one would not expect to find them at the surface of oxidized samples. An oxidized layer without vanadium does actually not show any of them [30], but vanadium admixing increases the reducibility. Therefore oxidation under the given conditions leads to the co-existence of indicators for reduction (the rods and BOV's) and signs of oxidation (the presence of oxidized vanadium at the regular surface and on the rods).

Figure 2e and f display an STM image and a LEED pattern of an oxidized layer with $14 \%$ of $\mathrm{V}$, respectively. The LEED pattern contains intense $(1 \times 2)$ spots, which show that the surface is now densely covered with the $(1 \times 2)$ reconstruction, as also recognizable in the STM image. There are additional structures at the surface, which give rise to an irregular pattern of protrusions in the STM image and to additional spots in the LEED pattern (marked by arrows). We attribute these structures to aggregates containing oxidized vanadium atoms, which partly have an oxidation state of 5+ as concluded from the XPS data (Fig. 1; Table 1). The presence of additional spots in the LEED pattern shows that at least part of the vanadium induced structures exhibits a long range order.

In order to check the reactivity of the samples, TPD test experiments with methanol as the probe molecule were conducted. Figure 3 compiles methanol [mass 31, Fig. 3a] and formaldehyde [mass 29, Fig. 3b] desorption spectra for different substrates. Apparently, the vanadium concentration has a significant impact on the structure of spectra. Characteristic desorption channels are marked by vertical blue lines in Fig. 3. In order to check whether the desorbing molecules contain substrate oxygen atoms, the mixed oxide layer was prepared with ${ }^{18} \mathrm{O}$ while the adsorbed methanol contained ${ }^{16} \mathrm{O}$. Desorbing methanol with ${ }^{18} \mathrm{O}$ (at mass 33 ) could not be detected, which excludes $\mathrm{C}=\mathrm{O}$ bond breaking in the methanol desorption channels. For the case of formaldehyde this conclusion cannot be drawn so simply since formaldehyde with ${ }^{18} \mathrm{O}$ would desorb at mass 31 , which is also the mass of methanol with ${ }^{16} \mathrm{O}$.

The four desorption channels are related to different features at the surface:

- Desorption at $680 \mathrm{~K}$ : this channel is due to methoxy groups on BOV's as has been shown recently [30]. As expected, this peak is intense for reduced $\mathrm{TiO}_{2}(110)$ without admixed vanadium, but it also shows up for oxidized layers with 3-6\% of vanadium. As already discussed, BOV's form on the surface of the mixed oxides even under oxidizing conditions at elevated temperatures due to the increased sample reducibility. The reducibility is higher for mixed oxides with a higher vanadium content, which is the reason why the intensity of this peak is higher for a vanadium concentration of 5\% than for concentrations of 1 and 3\%. However, for vanadium concentrations above $5 \%$ the intensity of the peak decreases due to the increasing density 
Fig. 3 a Methanol $(\mathrm{m} / \mathrm{z}=31)$ and $\mathbf{b}$ formaldehyde $(\mathrm{m} / \mathrm{z}=29)$ TPD spectra of methanol on oxidized $\mathrm{Ti}+\mathrm{V}$ thin films with various $\mathrm{V}$ concentrations $(1,3,5,6$, and $14 \%)$. Spectra of methanol on oxidized and reduced $\mathrm{TiO}_{2}(110)$ thin films without admixed vanadium are shown for comparison
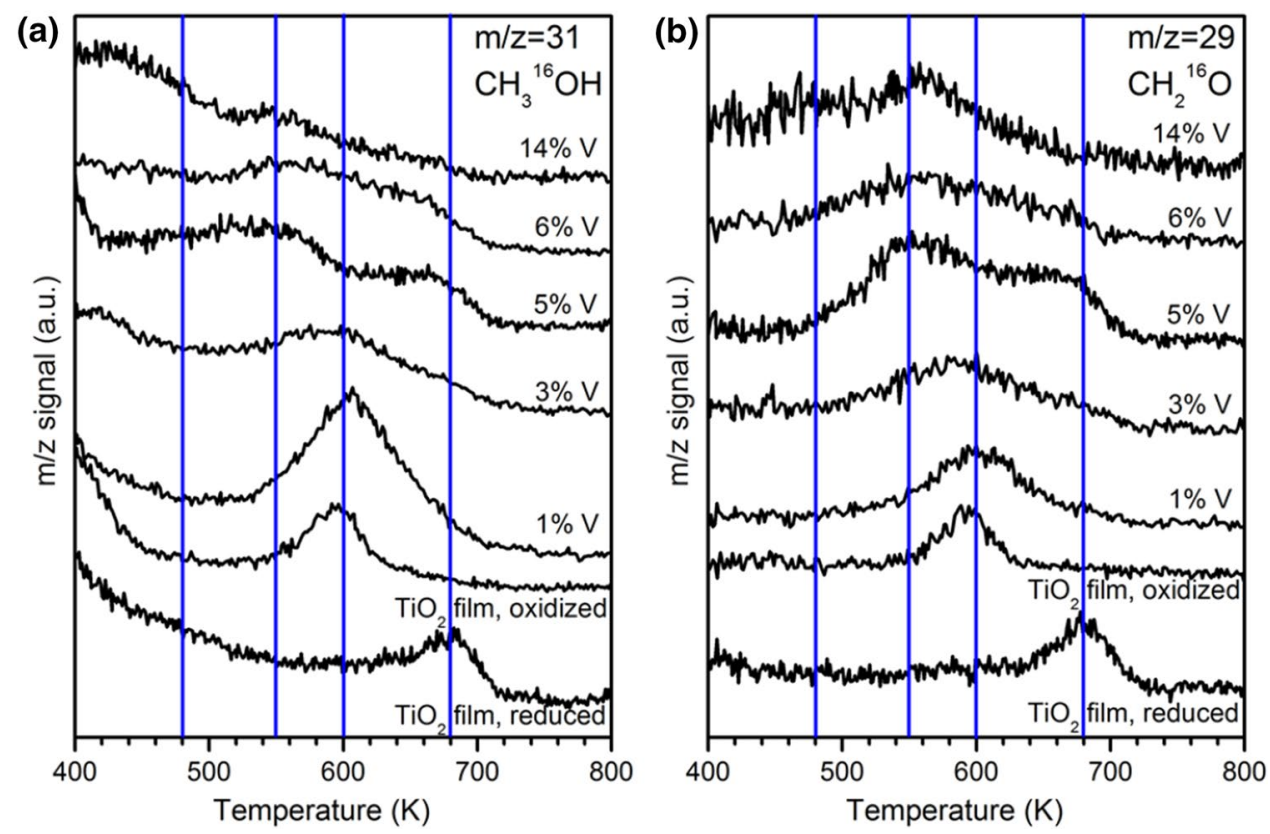

of $(1 \times 2)$ rods at the surface. Such an effect was also observed for reduced layers [19].

- Desorption at $600 \mathrm{~K}$ : this channel is related to the presence of oxygen adatoms at the surface. They are most abundant for small vanadium concentrations, since at higher concentrations vanadium-related clusters and the $(1 \times 2)$ rods occupy more and more of the surface area.

- Desorption at $\sim 550 \mathrm{~K}$ : The intensity in this channel is highest for vanadium concentrations of above $5 \%$, where a significant density of $(1 \times 2)$ rods decorated with vanadium related clusters is found at the surface, together with vanadium-related structures on the regular surface. At a vanadium concentration of $\sim 14 \%$ the intensity in this channel is still high while there is not much space at the surface, which is not covered with the $(1 \times 2)$ reconstruction. Therefore we tentatively attribute this channel to $(1 \times 2)$ rods decorated with vanadium-related features.

- Desorption at $\sim 480 \mathrm{~K}$ and lower: this channel is most intense for high vanadium concentrations where a large part of the surface is covered with the $(1 \times 2)$ reconstruction. According to XPS a significant part of the vanadium has a $5+$ oxidation state. Therefore we tentatively identify aggregates containing $\mathrm{V}^{5+}$ as reaction sites for the production of formaldehyde in this channel.

As a short summary we conclude that the formaldehyde production temperatures are smaller for sites where vanadium is involved as compared to sites where this is not the case. It also appears that $\mathrm{V}^{5+}$ lowers the reaction temperature below the reaction temperature of methoxy on sites, which do not involve $\mathrm{V}^{5+}$.
Several authors have published studies of methanol adsorption on vanadia layers on $\mathrm{TiO}_{2}(110)$. Wang and Madix reported $\mathrm{CH}_{2} \mathrm{O}$ desorption temperatures decreasing from 642 to 551 to $517 \mathrm{~K}$ with the vanadia coverage increasing from 0.3 ML to 0.6 ML to $1 \mathrm{ML}$ [12]. Wong et al. found that the $\mathrm{CH}_{2} \mathrm{O}$ desorption temperature is a function of the oxidation state of the vanadium cations [13]. A temperature of $615 \mathrm{~K}$ was reported to be related to clusters containing predominantly $\mathrm{V}^{3+}$, while clusters with $\mathrm{V}^{5+}$ were said to be responsible for the desorption at a lower temperature of $485 \mathrm{~K}$ [13]. These two papers did not report surface structure information, but they are in line with the results reported here in that the formaldehyde production temperature decreases with increasing vanadium coverage, at least for the investigated range of coverages.

Reactivity experiments combined with structure analysis were performed by Metiu and coworkers [17, 31, 32]. They found that post-oxidized $\mathrm{VO}$ aggregates on $\mathrm{TiO}_{2}$ produce formaldehyde at about $600 \mathrm{~K}$. With the help of STM experiments and density functional theory (DFT) calculations, they concluded that $\mathrm{VO}_{3}$ monomer clusters were responsible for this reaction channel. In the STM images of our oxidized layers the vanadia clusters are located above the Ti rows, while Metiu et al. found the $\mathrm{VO}_{3}$ aggregates in the upper threefold hollow sites. This difference is possibly to be attributed to the different preparation procedures. Metiu et al. deposited vanadia clusters onto $\mathrm{TiO}_{2}(110)$ at room temperature using an apparatus that produces mass-selected clusters while in our experiments vanadia clusters were produced by oxidation of vanadium atoms from subsurface areas of reduced $\mathrm{Ti}+\mathrm{V}$ mixed oxide layers. Another difference is that in the 
case reported here the vanadia clusters were supported by reduced $\mathrm{TiO}_{2}(110)$ layers with admixed vanadium, which may influence the cluster formation as well.

The morphology of vanadia clusters on $\mathrm{TiO}_{2}(110)$ with sub-monolayer coverages was also investigated by Agnoli et al. $[14,16]$. They found that vanadia clusters prepared by post oxidation of deposited vanadium atoms are located on top of the fivefold coordinated Ti substrate rows at low coverage $[14,16]$, which is the same location as in the present case. However, the authors report that the cluster have a height of $3.5 \AA$ [14], which is different from the $2.0 \AA$ found here. This may depend somewhat on the tunneling conditions: a bias voltage of $2.0 \mathrm{~V}$ and a tunneling current of $0.6 \mathrm{nA}$ were applied by Agnoli et al. while $2.5 \mathrm{~V}$ and $0.1 \mathrm{nA}$ were applied in our case.

We note that a vanadium doped substrate could be a more realistic model of powder catalyst supports than a non-doped substrate since a treatment at temperatures where vanadium may diffuse into the substrate is not uncommon. The titania supported vanadia powder model catalysts in the experiments of Beck et al. were prepared at $773 \mathrm{~K}$ [3], which is a temperature at which some vanadium unavoidably diffuses into the support where it may cause reduction depending on the preparation conditions, at least for a rutile support. In this context the confinement of the vanadium by the diffusion blocking layer is relevant, since this is the reason why a non-negligible sub-surface concentration of vanadium can be stabilized at all. In the case of powder samples this confinement is provided by the limited sized of the powder particles. Whether vanadium does diffuse into the support and increases the reducibility also for anatase supports has yet not been studied, but that thermodynamics leads to vanadium diffusion at high temperatures is not unlikely also for anatase and that this makes the anatase particles more reducible may be assumed also in the anatase case, since $\mathrm{V}^{4+}$ reduction will probably cost less energy than $\mathrm{Ti}^{4+}$ reduction also in anatase. This aspect was identified as the reason for the increased reducibility in the rutile case [19].

In the course of the methanol TPD experiments also ${ }^{18} \mathrm{O}_{2}$ traces (mass 36) were recorded. Some of the spectra are shown in Fig. 4 together with a spectrum of a surface without methanol and a spectrum of a $\mathrm{TiO}_{2}(110)$ layer without vanadium. There are four interesting aspects of these spectra:

- Oxygen desorption starts at lower temperature when the sample contains vanadium: This is expected since vanadium admixing increases the reducibility, as discussed before. At the surface of the pure $\mathrm{TiO}_{2}$ thin film and the layer with $1 \%$ of vanadium, the reaction of oxygen adatoms accounts for part of the oxygen desorption. Bulk and surface reduction contribute additional intensity.

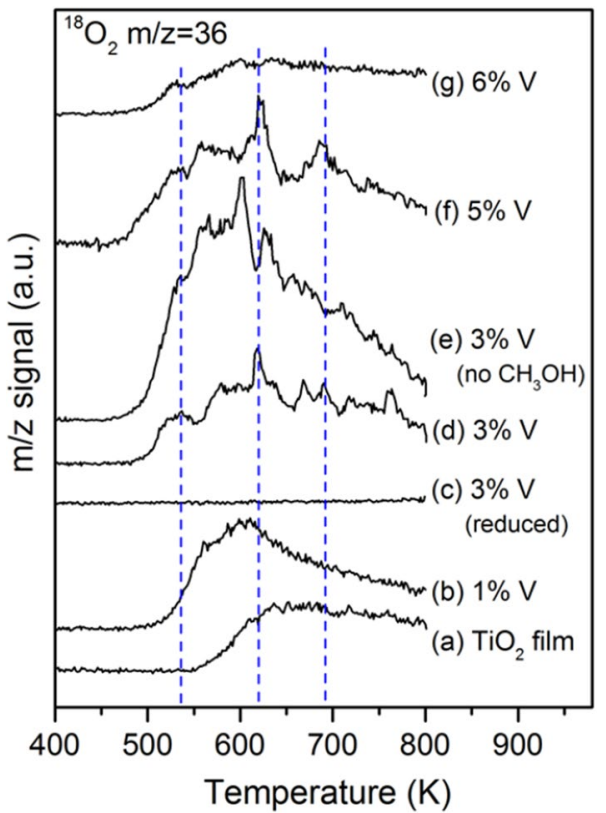

Fig. 4 Oxygen desorption spectra $\left({ }^{18} \mathrm{O}_{2}, \mathrm{~m} / \mathrm{z}=36\right)$ of methanol covered oxidized $\mathrm{Ti}+\mathrm{V}$ mixed oxide layers with different $\mathrm{V}$ concentrations. Spectra of an oxidized $\mathrm{TiO}_{2}(110)$ thin film $(a)$ and a reduced mixed oxide film with $3 \% \mathrm{~V}(c)$ are shown for comparison. Spectrum (e) was recorded without methanol dosing

- Oxygen desorption is not observed for a reduced sample: This is also expected since reduced samples offer many oxygen trapping sites.

- There is a complicated fine structure in the spectra for vanadium concentrations above $1 \%$ : The fine structure is not related to the presence of methanol at the surface since the spectrum of the surface without adsorbed methanol does also exhibit such a fine structure, although the presence of methanol appears to modify it. We attribute these features to oxygen-loss induced transformations of aggregates containing vanadium. The small FWHM (full width at half maximum) of the desorption peaks may indicate that the transformation is autocatalytic as observed before for the decomposition of formate and acetate on $\mathrm{Ni}(110)[33$, 34].

- The complexity is reduced for high vanadium concentrations: This may either mean that the contribution of vanadium containing aggregates on the $(1 \times 2)$ rods makes the spectra so complicated that the fine structure cannot be resolved anymore or it may mean that the fine structure is exclusively due to vanadium containing aggregates on the regular surface. 


\section{Conclusions}

We have studied the structure and the catalytic properties of well-ordered $\mathrm{Ti}+\mathrm{V}$ mixed oxide thin films after oxidation $\left(\mathrm{P}<10^{-6} \mathrm{mbar}\right)$ at elevated temperature $(600 \mathrm{~K})$ with methanol as the catalysis test molecule. Features related to oxidation co-exist with features related to reduction at the surface of the oxidized samples, which is attributed to the vanadium-induced increased sample reducibility [19]. The $\mathrm{O}_{2}$ release from the mixed oxide already at $450,80 \mathrm{~K}$ below the temperature found for oxidized $\mathrm{TiO}_{2}(110)$ without vanadium, is also attributed to this.

Four different formaldehyde production channels were identified: (1) Bridging oxygen vacancies induce formaldehyde formation at $680 \mathrm{~K}$. (2) The production of formaldehyde at $550 \mathrm{~K}$ is due to oxygen adatoms at the surface. (3) Formaldehyde production at $\sim 550 \mathrm{~K}$ is assigned to $(1 \times 2)$ rods decorated with clusters containing vanadium at vanadium concentrations above 5\%. (4) The formaldehyde desorption at $\sim 480$ and below is due to aggregates containing $\mathrm{V}^{5+}$, which cover the surface at vanadium concentration above $5 \%$.

We think that a model system in which the dopant atoms are confined to near-surface areas represents a more realistic model of supported catalysts since this confinement mimics the limited volume of support particles probably better than a model without confinement would do.

Acknowledgements Open access funding provided by Max Planck Society. We acknowledge the Deutsche Forschungsgemeinschaft (DFG) for funding through their collaborative research center 546, "Transition Metal Oxide Aggregates".

Open Access This article is distributed under the terms of the Creative Commons Attribution 4.0 International License (http://creativeco mmons.org/licenses/by/4.0/), which permits unrestricted use, distribution, and reproduction in any medium, provided you give appropriate credit to the original author(s) and the source, provide a link to the Creative Commons license, and indicate if changes were made.

\section{References}

1. Wachs IE (2005) Recent conceptual advances in the catalysis science of mixed metal oxide catalytic materials. Catal Today 100:79-94. https://doi.org/10.1016/j.cattod.2004.12.019

2. Bej SK, Rao MS (1991) Selective oxidation of n-butane to maleic anhydride 1. Optimization studies. Ind Eng Chem Res 30:18191824. https://doi.org/10.1016/0926-860X(92)85032-7

3. Beck B, Harth M, Hamilton NG et al (2012) Partial oxidation of ethanol on vanadia catalysts on supporting oxides with different redox properties compared to propane. J Catal 296:120-131. https ://doi.org/10.1016/j.jcat.2012.09.008

4. Abbott HL, Uhl A, Baron M et al (2010) Relating methanol oxidation to the structure of ceria-supported vanadia monolayer catalysts. J Catal 272:82-91. https://doi.org/10.1016/j. jcat.2010.03.009

5. Kropp T, Paier J, Sauer J (2014) Support effect in oxide catalysis: methanol oxidation on vanadia/ceria. J Am Chem Soc 136:1-6

6. Ganduglia-Pirovano MV, Popa C, Sauer J et al (2010) Role of ceria in oxidative dehydrogenation on supported vanadia catalysts. J Am Chem Soc 132:2345-2349. https://doi.org/10.1021/ja910 $574 \mathrm{~h}$

7. Biener J, Bäumer M, Wang J, Madix RJ (2000) Electronic structure and growth of vanadium on $\mathrm{TiO}_{2}(110)$. Surf Sci 450:12-26

8. Agnoli S, Castellarin-Cudia C, Sambi M et al (2003) Vanadium on $\mathrm{TiO}_{2}(110)$ : adsorption site and sub-surface migration. Surf Sci 546:117-126. https://doi.org/10.1016/j.susc.2003.09.019

9. Biener J, Bäumer M, Madix RJ (1999) A synchrotron study of the deposition of vanadia on $\mathrm{TiO}_{2}$ (110). Surf Sci 432:178-188

10. Price NJ, Reitz JB, Madix RJ, Solomon E (1999) A synchrotron XPS study of the vanadia-titania system as a model for monolayer oxide catalysts. J Electron Spectrosc Relat Phenom 98-99:257266. https://doi.org/10.1016/S0368-2048(98)00291-6

11. Wang Q, Madix RJ (2001) Preparation and reactions of $\mathrm{V}_{2} \mathrm{O}_{5}$ supported on $\mathrm{TiO}_{2}(110)$. Surf Sci Lett 474:L213-L216

12. Wang Q, Madix RJ (2002) Partial oxidation of methanol to formaldehyde on a model supported monolayer vanadia catalyst: vanadia on $\mathrm{TiO}_{2}(110)$. Surf Sci 496:51-63. https://doi.org/10.1016/S0039 $-6028(01) 01600-4$

13. Wong GS, Concepcion MR, Vohs JM (2003) Reactivity of monolayer $\mathrm{V}_{2} \mathrm{O}_{5}$ films on $\mathrm{TiO}_{2}(110)$ produced via the oxidation of vapor-deposited vanadium. Surf Sci 526:211-218. https://doi. org/10.1016/S0039-6028(03)00006-2

14. Agnoli S, Sambi M, Granozzi G et al (2004) The growth of ultrathin films of vanadium oxide on $\mathrm{TiO}_{2}(110)$. Surf Sci 562:150-156. https://doi.org/10.1016/j.susc.2004.05.118

15. Kim HY, Lee HM, Metiu H (2010) Oxidative dehydrogenation of methanol to formaldehyde by a vanadium oxide cluster supported on rutile $\mathrm{TiO}_{2}(110)$ : which oxygen is involved?. J Phys Chem C 114:13736-13738. https://doi.org/10.1021/jp103361v

16. Artiglia L, Agnoli S, Vittadini A et al (2013) Atomic structure and special reactivity toward methanol oxidation of vanadia nanoclusters on $\mathrm{TiO}_{2}(110)$. J Am Chem Soc 135:17331-17338

17. Price SP, Tong X, Ridge C et al (2014) Catalytic oxidation of methanol to formaldehyde by mass-selected vanadium oxide clusters supported on $\mathrm{TiO}_{2}(110)$ surface. J Phys Chem A 2:83098313. https://doi.org/10.1021/jp5011378

18. Artiglia L, Agnoli S, Savio L et al (2014) From vanadia nanoclusters to ultrathin films on $\mathrm{TiO}_{2}(110)$ : evolution of the yield and selectivity in the ethanol oxidation reaction. ACS Catal 4:3715-3723

19. Song X, Primorac E, Kuhlenbeck H, Freund HJ (2016) Effect of vanadium admixing on the surface structure of $\mathrm{TiO}_{2}(110)$ under non-oxidizing conditions. Surf Sci 653:181-186

20. Feulner P, Menzel D (1980) Simple ways to improve "flash desorption" measurements from single crystal surfaces. J Vac Sci Technol 17:662-663. https://doi.org/10.1116/1.570537

21. Horcas I, Fernández R, Gómez-Rodríguez JM et al (2007) WSXM: a software for scanning probe microscopy and a tool for nanotechnology. Rev Sci Instrum 78:013705-013712. https://doi. org/10.1063/1.2432410

22. Végh J (1988) The analytical form of the Shirley-type background. J Electron Spectrosc Relat Phenom 46:411-417

23. Göpel W, Anderson JA, Frankel D et al (1984) Surface defects of $\mathrm{TiO}_{2}(110)$ : a combined XPS, XAES and ELS study. Surf Sci Lett 139:333-346. https://doi.org/10.1016/0167-2584(84)90456-0

24. Diebold U, Madey TE, Diebold U (1996) $\mathrm{TiO}_{2}$ by XPS. Surf Sci Spectra 4:227-231. https://doi.org/10.1116/1.1247794 
25. Silversmit G, Depla D, Poelman H et al (2004) Determination of the V2p XPS binding energies for different vanadium oxidation states $\left(\mathrm{V}^{5+}\right.$ to $\left.\mathrm{V}^{0+}\right)$. J Electron Spectrosc Relat Phenom 135:167175. https://doi.org/10.1016/j.elspec.2004.03.004

26. Wendt S, Schaub R, Matthiesen J et al (2005) Oxygen vacancies on $\mathrm{TiO}_{2}(110)$ and their interaction with $\mathrm{H}_{2} \mathrm{O}$ and $\mathrm{O}_{2}$ : a combined high-resolution STM and DFT study. Surf Sci 598:226-245. https ://doi.org/10.1016/j.susc.2005.08.041

27. Onishi H, Iwasawa Y (1994) Reconstruction of $\mathrm{TiO}_{2}(110)$ surface: STM study with atomic-scale resolution. Surf Sci 313:L783L789. https://doi.org/10.1016/0039-6028(94)91146-0

28. Bowker M, Bennett $\mathrm{R}$ (2009) The role of $\mathrm{Ti}^{3+}$ interstitials in $\mathrm{TiO}_{2}(110)$ reduction and oxidation. J Phys Condens Matter 21:474224-474232. https://doi.org/10.1088/09538984/22/5/059801

29. Yim CM, Pang CL, Thornton G (2015) Probing the local electronic structure of the cross-linked $(1 \times 2)$ reconstruction of rutile $\mathrm{TiO}_{2}(110)$. Surf Sci 650:71-75. https://doi.org/10.1016/j. susc.2015.04.022
30. Song X, Primorac E, Kuhlenbeck H, Freund H-J (2016) Decoupling a thin well-ordered $\mathrm{TiO}_{2}(110)$ layer from a $\mathrm{TiO}_{2}(110)$ substrate with a Ti + Ta mixed oxide interlayer. J Phys Chem C 120:8185-8190. https://doi.org/10.1021/acs.jpcc.6b01318

31. Shapovalov V, Metiu H (2007) $\mathrm{VO}_{\mathrm{x}}(\mathrm{x}=1-4)$ submonolayers supported on rutile $\mathrm{TiO}_{2}(110)$ and $\mathrm{CeO}_{2}(111)$ surfaces: the structure, the charge of the atoms, the XPS spectrum, and the equilibrium composition in the presence of oxygen. J Phys Chem C 111:14179-14188. https://doi.org/10.1021/jp0744811

32. Price SP, Tong $X$, Ridge $C$ et al (2011) STM characterization of size-selected $\mathrm{V}_{1}, \mathrm{~V}_{2}, \mathrm{VO}$, and $\mathrm{VO}_{2}$ clusters on a $\mathrm{TiO}_{2}(110)-(1 \times$ 1) surface at room temperature. Surf Sci 605:972-976. https://doi. org/10.1016/j.susc.2011.02.016

33. Falconer JL, Madix RJ (1974) The kinetics and mechanism of the autocatalytic decomposition of $\mathrm{HCOOH}$ on clean $\mathrm{Ni}(110)$. Surf Sci 46:473-504

34. Alemozafar AR, Madix RJ (2004) The role of surface deconstruction in the autocatalytic decomposition of formate and acetate on Ni (110). J Phys Chem B 108:14374-14383 